\title{
Some morphological traits of the fruit and apricot stone of Dagestan origin at the different ripening periods
}

\author{
Dzhalaludin M. Anatov ${ }^{1 *}$ \\ ${ }^{1}$ Mountain Botanical Garden DFRC RAS, 45 Str. M. Gadjiev, Makhachkala, Russia
}

\begin{abstract}
The paper presents the results of a comparative study of the cultivated and wild-growing apricot of Dagestan origin according to the morphological characteristics of the fruit and stone at different ripening periods. The pomological evaluation showed that the shape index of the fruit changes by one gradation regardless of the origin of the genotype, while the shape of the stone does not change and remains constant for all genotypes. For example, the fruit of the Kamil cultivar has an ovate shape at an early ripening period, and a circular one at late ripening. During ripening, the weight of the fruit doubles (1.8-2.6 times), while the ratio of stone mass to the weight of the fruit decreases (1.8-2.5 times). For cultivars and wild-growing forms, differences in the change in the linear dimensions and mass of the stone at different maturation periods were noted. The morphological characteristics of the fruit and stone in terms of the coefficient of variation $(\mathrm{CV})$ vary more at the later stages of ripening, and in general are higher in cultivars than in wild plants, and the endocarp varies less than the fruit, at all periods of ripening.
\end{abstract}

\section{Introduction}

Apricot (Prunus armeniaca L.) as a fruit crop has a wide geographic distribution. The significance of this culture for humanity is great $[1,2,3]$.

The size and shape of fruits and apricot kernels affect the market value and are important physical characteristics in the sorting, storage, packaging and transportation of fruits and the design of appropriate equipment $[4,5,6,7,8,9]$. The fruits of the wildgrowing apricot are a valuable source of nutrition for the regions of its growth $[10,11]$

In addition, pomological traits of fruits and kernels, their shape are important in determining the variety [12]. The indices of the ratio of width to length and thickness to width are used as criteria. It is also important to determine the endocarp maturity of apricot kernels, which affects the time of harvest, its physical and biochemical characteristics [13, $14,15]$.

Based on this, the purpose of this study was to determine the morphological characteristics of the fruit and stone of two cultivars and two wild forms of apricot at different ripening periods using statistical methods of analysis.

\footnotetext{
*Corresponding author: djalal@list.ru
} 


\section{Material and methods}

For measurements, fruits were taken from two cultivars (Seedling Shindahlana, Kamil) and two wild-growing forms (Form 1, Form 2) in the conditions of the Tsudakhar experimental base of the Mountain Botanical Garden of the DFRC RAS. To assess endocarp maturity, fruits were harvested at two stages of ripening: the first group (early) was selected at the end of June (green fruit), the second group (late) - a month later at the stage of technological maturity.

For the fruit, length (Lf), width (Wf), thickness (Tf), weight (Mf), and similar traits for endocarp (Ls, Ws, Ts, Ms), as well as index indicators such as fruit stone percentage (Ms / Mf), fruit shape index (Wf / Lf) and stone (Ws / Ls), fruit thickening index (Tf / Wf) and endocarp (Ts / Ws). Measurements of apricot fruits and stones were carried out using a caliper and electronic scales with an accuracy of $0.01 \mathrm{~mm}$ and $0.001 \mathrm{~g}$, respectively.

Morphological variability of fruit traits was assessed using univariate statistics for each accession and maturity. Statistical processing of the obtained results and assessment of the reliability of differences was carried out according to the Student's t-test, using the Statistica v.13 software.

\section{Results and discussion}

Pomological evaluation of the genotypes according to the ripening time showed that the shape of the fruit changes by one gradation, regardless of the origin of the genotype (table 1). Moreover, for cultivars, this ratio of width to length changes on average by $7 \%$, and for wild ones by $10 \%$. In this case, the shape of the stone does not change and remains constant for all genotypes.

Table 1. Gradation of apricot genotypes by fruit and stone shape at different ripening periods

\begin{tabular}{|c|c|c|c|}
\hline \multirow[t]{2}{*}{ Genotypes } & \multirow[t]{2}{*}{ Category } & \multicolumn{2}{|c|}{ Shape Gradation } \\
\hline & & early & late \\
\hline \multirow[t]{2}{*}{ Seyanets Shindakhlana } & Fruit & circular & oblate \\
\hline & Stone & ovate & ovate \\
\hline \multirow[t]{2}{*}{ Kamil } & Fruit & ovate & circular \\
\hline & Stone & oblong & oblong \\
\hline \multirow[t]{2}{*}{ Form 1} & Fruit & circular & oblate \\
\hline & Stone & ovate & ovate \\
\hline \multirow[t]{2}{*}{ Form 2} & Fruit & circular & oblate \\
\hline & Stone & circular & circular \\
\hline
\end{tabular}

Comparative results of the obtained data showed that the linear dimensions of the fruits and their indices change significantly for apricots at different phases, while the traits of the stone are almost indistinguishable (table 2). The mass of the fruit increases by 2 times (1.82.6 times), while the ratio of the mass of the stone to the mass of the fruit decreases (1.8-2.5 times). The size and weight of the stone decreases slightly at the stage of full maturation, which may indicate the outflow of some of the macronutrients from the endocarp towards an increase in the mesocarp. In wild-growing forms, with a decrease in linear dimensions, the mass of the endocarp slightly increases, i.e. the stone becomes denser, which may indicate the outflow of macronutrients from the endocarp to the kernel as it ripens. Such processes can speak about the adaptive strategy of wild-growing forms aimed at increasing the macronutrients of the kernel, and hence the reproductive potential.

The variability of the fruit and stone in terms of the coefficient of variation (CV) is 
higher at late maturity, and is generally lower in wild-growing genotypes than in cultivars.

The size and weight of the endocarp vary less than the fruit, at all ripening periods.

Table 2. Descriptive statistics of morphological characteristics of the apricot fruit

\begin{tabular}{|c|c|c|c|c|c|c|c|c|c|c|c|c|}
\hline ar & ean & St.d. & $\mathrm{CV}$ & Mean & St.d. & $\mathrm{CV}$ & Tean & t.d. & $\mathrm{CV}$ & Mean & St.d. & $\mathrm{CV}$ \\
\hline & \multicolumn{6}{|c|}{ Seyanets Shindakhlana } & \multicolumn{6}{|c|}{ Kamil } \\
\hline & \multicolumn{3}{|c|}{ early $n=30$} & \multicolumn{3}{|c|}{ late $n=20$} & \multicolumn{3}{|c|}{ early $n=30$} & \multicolumn{3}{|c|}{ late $n=30$} \\
\hline $\mathrm{Lf}$ & 3,10 & 1,56 & 5,5 & 33,62 & 2,57 & 7,7 &, 67 & 1,71 & 5,8 & 3,28 & 1,63 & 4,9 \\
\hline $\mathrm{Wf}$ & 27,27 & ,43 & 5,2 & 35,07 & 3,14 & 9,0 & & 1,74 & 6,7 & 31 & 2,44 & 7,8 \\
\hline $\mathrm{Tf}$ & & 02 & 8,6 & 32,85 & 2,6 & 8,0 & & 1,74 & 7,8 & & 2,23 & 7,8 \\
\hline $\mathrm{Mf}$ & & 56 & 15 & & 5,44 & 22,8 & & 11 & & & 38 & 19,8 \\
\hline$\overline{\mathrm{Ls}}$ & & & 4, & & & 7 & & & & & 10 & 4,5 \\
\hline Ws & & 93 & 5 & & 1,23 & 0,9 & &, 13 & & & 0,97 & 5,3 \\
\hline Ts & & 76 & 6 , & & 1,86 & 7,7 & &, 76 & & & 0,98 & 8,1 \\
\hline Ms & & 25 & 13,6 & & 0,31 & 17,8 & & 0,37 & & & 0,30 & 14,5 \\
\hline $\mathrm{Ms} / \mathrm{M}$ & & 2,05 & 11,3 & 7,44 & 0,94 & 12,7 & 2,80 & 4,52 & 19,8 & 33 & 1,62 & 13,2 \\
\hline$/ \mathrm{Lf}$ & & 3,64 & 3,8 & 104,28 & 3,77 & 3,6 & 37,14 & 3,48 & 4 & 03 & 4,95 & 5,3 \\
\hline & & 68 & 3 , & & 3,1 & 3, & & 3,50 & & & 3,24 & 4,3 \\
\hline $\mathrm{Wf}$ & & 26 & 7,3 & ב & 4,34 & 4,6 & 6,24 & 3,02 & 3 & 95 & 3,54 & 3,9 \\
\hline \multirow[t]{3}{*}{ Ts/Ws } & & 3,99 & 6,4 & 62,75 & 5,05 & 8,0 & 6,78 & 4,14 & 6 , & 66,15 & 4,67 & 7,1 \\
\hline & \multicolumn{6}{|c|}{ Form 1} & \multicolumn{6}{|c|}{ Form 2} \\
\hline & \multicolumn{3}{|c|}{ early $n=30$} & \multicolumn{3}{|c|}{ late $n=30$} & \multicolumn{3}{|c|}{ early $n=30$} & \multicolumn{3}{|c|}{ late $n=30$} \\
\hline L & 15 & 1,00 & $\overline{4}$ & 76 & 1,64 & $\overline{5,5}$ & 47 & 0,61 & & 84 & 1,32 & 5,5 \\
\hline W & & & 5 , & & 1 , & $\mathrm{J}$ & & 0,76 & & & 1,60 & 6,2 \\
\hline$\overline{T f}$ & 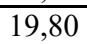 & 0,89 & 4 & & 1,61 & 5,5 & 16,66 & 0,52 & & & 1,31 & 5,4 \\
\hline $\mathrm{Mf}$ & & 0,91 & 14,3 & 16,20 & 2,29 & 14,1 & 3,69 & 0,32 & 8, & 8,20 & 1,26 & 15,3 \\
\hline Ls &, 77 & 0,75 & 4,0 & 18,27 & 0,79 & 4,3 & 17,04 & 0,64 & 3 & 16,24 & 0,82 & 5,1 \\
\hline$\overline{\mathrm{Ws}}$ & 16,25 & 0,75 & 4,6 & 16,38 & 0,66 & 4,0 & 15,62 & 0,51 & 3, & 15,60 & 0,74 & 4,8 \\
\hline Ts & 11,09 & 0,38 & 3,5 & 11,01 & 0,40 & 3,6 & 10,66 & 0,36 & 3 & 10,72 & 0,35 & 3,3 \\
\hline$\sqrt{M}$ & & 0,15 & 11,0 & 1 & 0,16 & 10,8 & 1,18 & 0,10 & 8, & 1, & 0,14 & 11,3 \\
\hline & & 1,74 & 8,0 & & 0,61 & 6,9 & 32,14 & 3,79 & 11,8 & & 1,31 & 8,5 \\
\hline $\mathrm{Wf} / \mathrm{Lf}$ & 98,59 & 3,33 & 3,4 & 107,00 & 4,39 & 4,1 & 96,89 & 3,39 & 3, & 107,94 & 4,47 & 4,1 \\
\hline $\mathrm{Ws} / \mathrm{Ls}$ & 86,62 & 2,55 & 2,9 & 89,74 & 3,23 & 3,6 & 91,75 & 3,29 & 3 , & 96,13 & 2,83 & 3,0 \\
\hline & & 2,85 & 3 & & 4,09 & 4,5 & 84,07 & 1,99 & & & 2,97 & 3,2 \\
\hline Ts/Ws & 68,29 & 2,60 & 3,8 & 67,28 & 1,94 & 2,9 & 68,32 & 2,61 & 3,8 & 68,79 & 2,13 & 3,1 \\
\hline
\end{tabular}

To investigate whether endocarp parameters change with maturity, an intergroup comparison was performed for each genotype by Student's t-test (Table 3). We will not focus on the differences in terms of maturation for the traits of the fruit, since these parameters change significantly. In cultivars, there were no significant differences in endocarp maturity, with the exception of Kamil, who had significant differences in the stone shape index. For both wild-growing forms, slight significant differences were noted in the length and shape of the stone, and in Form 2, in the mass of the stone. Differences in index traits are higher in wild-growing genotypes relative to cultivated ones. 
Table 3. Significance of differences in the morphological characteristics of the fruit at different periods of maturation according to criterion t-test

\begin{tabular}{|l|l|l|l|l|l|l|}
\hline Variable & $\begin{array}{l}\text { Seyanets } \\
\text { Shindakhlana }\end{array}$ & Kamil & Form 1 & Form 2 & Cultivars & Wild \\
\hline Lf & $9,46^{* * *}$ & $8,35^{* * *}$ & $15,97^{* * *}$ & $12,70^{* * *}$ & $12,34^{* * *}$ & $8,93^{* * *}$ \\
\hline Wf & $11,92^{* * *}$ & $9,97^{* * *}$ & $20,73^{* * *}$ & $18,22^{* * *}$ & $12,76^{* * *}$ & $12,99^{* * *}$ \\
\hline Tf & $14,27^{* * *}$ & $11,91^{* * *}$ & $27,98^{* * *}$ & $29,17^{* * *}$ & $14,68^{* * *}$ & $19,29^{* * *}$ \\
\hline Mf & $13,09^{* * *}$ & $10,32^{* * *}$ & $21,96^{* * *}$ & $19,04^{* * *}$ & $13,28^{* * *}$ & $11,90^{* * *}$ \\
\hline Ls & 0,29 & 0,68 & $2,52^{*}$ & $4,20^{* * *}$ & 0,44 & $2,94^{* *}$ \\
\hline Ws & 0,46 & 1,03 & 0,70 & 0,10 & 0,56 & 0,40 \\
\hline Ts & 0,28 & 0,38 & 0,71 & 0,63 & 0,57 & 0,09 \\
\hline Ms & 1,09 & 0,62 & 1,54 & $2,29^{* *}$ & 0,57 & $2,14^{*}$ \\
\hline Wf/Lf & $6,70^{* * *}$ & $6,24^{* * *}$ & $8,36^{* * *}$ & $10,79^{* * *}$ & $4,86^{* * *}$ & $13,46^{* * *}$ \\
\hline Ws/Ls & 1,17 & $2,11^{*}$ & $4,15^{* * *}$ & $5,53^{* * *}$ & 0,13 & $4,94^{* * *}$ \\
\hline Tf/Wf & $4,82^{* * *}$ & $5,53^{* * *}$ & $9,42^{* * *}$ & $15,34^{* * *}$ & $6,84^{* * *}$ & $16,12^{* * *}$ \\
\hline Ts/Ws & 0,16 & 0,55 & 1,71 & 0,77 & 0,15 & 0,62 \\
\hline N
\end{tabular}

Note: The significance of the differences at $*-\mathrm{P}<0,05 ; * *-\mathrm{P}<0,01 ; * * *-\mathrm{P}<0,001$

\section{Conclusions}

On the basis of a comparative study of the cultivated and wild-growing apricot of Dagestan origin, the main morphological changes in the size and weight of the fruit and stone were established at different periods of ripening. It was found that the shape of the fruit increases by one gradation regardless of the origin of the genotype during pomological evaluation. In this case, the shape of the stone does not change and remains constant for all genotypes. From early to late ripening, the weight of the fruit increases approximately twofold (1.8-2.6 times), with a decrease in the ratio of the mass of the stone to the weight of the fruit (1.82.5 times). For cultivars and wild-growing forms, differences in the change in the size and mass of the stone were noted. In cultivars, a decrease in the size and mass of the stone may indicate the outflow of some of the macronutrients from the endocarp to the mesocarp, while in wild forms, the mass of the stone slightly increases, which may indicate an adaptive strategy of wild-growing forms aimed at increasing the energy substances of the kernel, and therefore the reproductive potential. Coefficient of variation (CV) traits of fruit and stone vary more at late maturity, and are lower in wild forms than cultivars. The size and weight of the endocarp varies less than the fruit, at all ripening periods.

The obtained results of research on the size, weight and shape of fruits and apricot stones can be used for the identification of varieties, selection, as well as for determining the parameters of the equipment of machines for collection, sorting and post-harvest processing of fruits.

\section{Acknowledgements}

The work was supported by RFBR grant №19-016-00133A.

\section{References}

1. K. U. Yilmaz, K. Gurcan, (Rijeka: Crotia, 249-270 2012) https://www.intechopen.com/books/genetic-diversity-in-plants/genetic-diversity-inapricot

2. Z.M. Asadulaev, D.M. Anatov and M.A. Gaziev, Acta Hort., 1032, 183-190 (2014) 
https://doi.org/10.17660/ActaHortic.2014.1032.24

3. Z.M. Asadulaev, D.M. Anatov, Arid Ecosystems, 9 (2), 104-110 (2019) https://doi.org/10.1134/S2079096119020021

4. T. Milosevic, N. Milosevic, I. Glisic, Tarim Bilim. Derg, 17, 167-176 (2011) http://dergiler.ankara.edu.tr/dergiler/15/1729/18371.pdf

5. E. Mratinić, B. Popovski, T. Milošević, M. Popovska, Not. Sci. Biol., 3, 105-112 (2011) https://doi.org/10.15835/nsb346410

6. K.U. Yilmaz, S. Paydaş Kargi, S. Kafkas, J. Turk.. Agric. For., 36, 688-694 (2012) https://dergipark.org.tr/tr/download/article-file/119491

7. T. Milošević, N. Milošević, I. Glišić, I.S .Glišić, Acta Sci. Pol., 13(5), 77-90 (2014) http://www.acta.media.pl/pl/full/7/2014/000070201400013000050007700090.pdf

8. E. Mratinić, B. Popovski, T. Milošević, M. Popovska, J. Agr. Sci. Tech., 13, 11211134 (2011) https://pdfs.semanticscholar.org/d597/13909480cee339627c7276e1d1251 5e5b9b7.pdf?_ga=2.155839035.1641320137.1597234655-2093477876.1597234655

9. A. E. Kate, P.P. Sutar, Journal of Food Science, 85(2), 432-441 (2020) https://doi.org/10.1111/1750-3841.15009

10. H. Pinar, M. Unlu, S. Ercisli, A. Uzun, M. Bircan, K.U. Yilmaz, G. Agar, Journal of Applied Botany and Food Quality, 86(1), 55-58 (2013) https://doi.org/10.5073/JABFQ.2013.086.008

11. S. Malik, R. Chaudhury, O. Dhariwal, S. Mir, Plant Genetic Resources, 8(3), 249-257 (2010) https://doi.org/10.1017/S1479262110000304

12. Y. Li, T. Smith, C.J .Liu, N. Awasthi, J. Yang, Y.F. Wang, C.S. Li, Taxon, 60, 555564 (2011) https://doi.org/10.1002/tax.602021

13. Y. Zheng, G.W. Crawford, X. Chen, PLoS One. 9(9), (2014) https://doi.org/10.1371/journal.pone.0106595

14. X. Zhang, L. Zhang, Q. Zhang, J. Xu, W. Liu, W. Dong, BMC Plant Biol., 17(72), (2017) https://doi.org/10.1186/s12870-017-1023-5

15. S.M. Wani, F.A. Masoodi, T.A. Wani, M. Ahmad, A. Gani, S.A. Ganai, Cogent Food \& Agriculture, 1(1), (2015) https://doi.org/10.1080/23311932.2015.1118961 